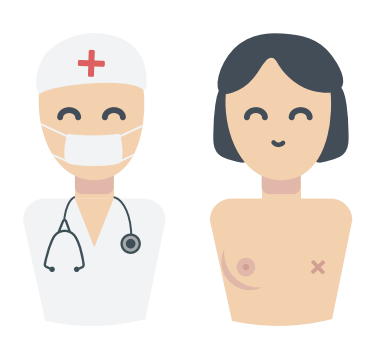

\title{
CUIDADOS PALIATIVOS REALIZADOS PELO ENFERMEIRO A MULHERES COM CÂNCER DE MAMA
}

\author{
HOSPICE CARE PERFORMED BY NURSES WOMEN WITH BREAST CANCER \\ IN EXTREME VULNERABILITY
}

\begin{abstract}
Joana Gabryella Maia da Silva
Enfermeira pela Universidade Potiguar - UnP, Pós-graduada em Gestão Hospitalar e de Serviços de Saúde.

E-mail: jjoana_gaby@hotmail.com

Donátila Cristina Lima Lopes

Enfermeira. Pós-graduada em Gestão Hospitalar e de Serviços de Saúde. Membro do Grupo de Pesquisa Caleidoscópio da Educação em Enfermagem da Universidade Federal do Rio Grande do Norte - UFRN.

Natal-RN, Brasil. E-mail: donatila.lima@gmail.com

Luana Maria Galdino da Silva Vilar

Enfermeira. Pós-graduada em Oncologia e Gestão Hospitalar e de Serviços de Saúde.

E-mail: luanavilar_jc@yahoo.com.br

Danielle Karla de Araújo Duarte

Enfermeira pela Universidade Potiguar - UnP, Pós-graduada em Gestão Hospitalar e de Serviços de Saúde.

E-mail: daniellekarla7@yahoo.com.br

Rosângela Symara Lima de Araújo

Enfermeira. Pós-Graduada em Enfermagem. Docente da Universidade Potiguar - UnP.

E-mail: rosangela.araujo@unp.br
\end{abstract}

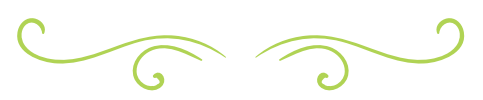

\section{RESUMO}

O câncer de mama é uma patologia de alta incidência na atualidade, afetando principalmente o gênero feminino. É uma doença que afeta o emocional e físico da mulher e, diante deste quadro, os cuidados paliativos tornam-se uma estratégia de cuidado essencial para proporcionar uma melhor qualidade de vida a estas pacientes. Esta pesquisa tem como objetivo identificar o perfil das mulheres com câncer de mama em vulnerabilidade extrema e o que dizem os estudos na literatura nacional sobre os cuidados paliativos do enfermeiro direcionado a essas mulheres. Trata-se de uma revisão da literatura

integrativa realizada por meio de consulta a artigos científicos nas bases de dados científicas da Biblioteca Regional de Medicina, LILACS e Scielo. Selecionamos 12 artigos que abordavam os cuidados paliativos em mulheres com câncer de mama em vulnerabilidade extrema. Os resultados apontam que os cuidados paliativos a estas mulheres devem ser fundamentados num sistema de valores humanísticos universais, tais como a amabilidade, o respeito e o afeto por si. O cuidado paliativo de enfermagem está na promoção do diálogo, no saber ouvir, na segurança, na valorização das queixas 
e no apoio aos familiares. As ações incluem medidas terapêuticas para o controle dos sintomas físicos, intervenções psicoterapêuticas e apoio espiritual ao paciente do diagnóstico ao óbito. Conclui-se que o cuidado paliativo às pacientes com câncer de mama ganhou seu espaço e se transformou em um método de cuidar que veio para proporcionar uma nova metodologia da assistência com resultados positivos, tanto para a paciente como para a sua família.

Palavras-chave: Câncer de mama. Cuidados Paliativos. Enfermeiro.

\section{ABSTRACT}

Breast cancer is a disease of high incidence today, affecting mainly females. It is a disease that affects the emotional and physical of the woman and, on this table, palliative care become an essential care strategy to provide a better quality of life for these patients. The research aims to identify the profile of women with breast cancer in extreme vulnerability and what they say studies in the national literature on palliative care nurses to these women. This is a review of integrative literature conducted through consultation in scientific articles in scientific databases of the Regional Library of Medicine, Lilacs and Scielo. We selected 12 articles covering palliative care for women with breast cancer in extreme vulnerability. The results indicate that palliative care to these women must be grounded in universal humanistic values system, such as kindness, respect and affection for you. The nursing palliative care is the promotion of dialogue, listening, security, recovery of claims and support their families. Actions include therapeutic measures for the control of physical symptoms, psychotherapeutic interventions and spiritual support to the patient from diagnosis to death. We conclude that palliative care to breast cancer patients won their space and turned into a method of care that came to provide a new methodology of counseling with positive results for both the patient and his family.

Keywords: Breast câncer. Palliative Care. Nurse.

\section{INTRODUÇÃO}

As neoplasias malignas possuem bases genéticas e moleculares que podem ser reconhecidas como agravos genéticos causados por instabilidade genômica, de acordo com a fisiopatologia da doença (ROBSON et al., 2010).

As células que formam os tecidos do corpo humano são naturalmente capazes de se multiplicar por meio de um processo contínuo, o que não ocorre nas células do câncer, que passam a se multiplicar de forma desordenada podendo expandir pelos tecidos e órgãos vizinhos. Na fisiologia, a maioria das células normais cresce, multiplica-se e morre de maneira ordenada, porém, nem todas as células normais são iguais: algumas nunca se dividem, como os neurônios (INCA, 2011).

Sabe-se que a neoplasia maligna da mama tem repercussão no mundo por ser o segundo tipo de câncer mais incidente, sendo registrados, a cada ano, mais de 1,6 milhões de casos novos e pouco mais de 521 mil óbitos pela doença (FERLAY et al., 2012).

Nos últimos anos, o câncer de mama vem se constituído na primeira causa de morte por câncer na população feminina, registrando-se aumento das taxas de mortalidade, ajustadas por idade pela população mundial, de 38\% (variação percentual relativa), entre os anos de 1979 e 2011. Em países desenvolvidos a incidência de câncer de mama cresce cada vez mais e o mais preocupante é saber que envolve índices de mortalidade pela doença. Todavia, esse dado está associado à utilização de métodos eficientes de detecção precoce e à oferta de tratamento adequado (INSTITUTO 
NACIONAL DE CÂNCER JOSÉ ALENCAR GOMES DA SILVA, 2011).

Segundo estimativa do Inca, o Rio grande do Norte (RN) terá 8.470 novos casos de câncer de todos os tipos no biênio 2018/2019 (INCA, 2018). As estimativas são feitas em cima das taxas brutas e ajustadas de incidência por 100 mil habitantes e do número de casos novos de câncer.

Foram detectados pela Liga Norte-riograndense Contra o Câncer, até o mês de junho 2018, 331 novos casos de câncer de mama. Em 2017 foram diagnosticados 702 novos casos e em 2016, 692 novos casos, dados somados das quatro unidades de atendimento da instituição: Centro Avançado de Oncologia (Cecan), Hospital Doutor Luiz Antônio, Policlínica e Hospital de Oncologia do Seridó (LIGA CONTRA O CÂNCER, 2018).

Tais unidades de referência em câncer têm um nível da atenção capacitado para determinar a extensão da neoplasia (estadiamento), tratar, cuidar e assegurar a qualidade dos serviços de assistência oncológica. Contudo, a definição do tempo de atraso pode compreender três momentos distintos: o primeiro ocorre dos primeiros sintomas até a primeira consulta médica; o segundo compreende o período entre a primeira consulta até 0 primeiro acesso ao serviço de referência especializado; e o terceiro, da primeira avaliação no serviço especializado até o tratamento específico. Em consonância com a Portaria $n^{\circ}$. 876/11 da Lei $n^{\circ}$. 12.732/12 do Ministério da Saúde, o tempo entre o registro do diagnóstico de câncer no prontuário médico e o início do tratamento não deve ultrapassar 60 dias (BRASIL, 2013).

De acordo com o guia para entender o laudo médico de câncer de mama, existem três graus de câncer: grau 1 (baixo grau ou bem diferenciado) em que as células cancerosas são um pouco diferentes das células normais e são, geralmente, de progressão lenta; grau 2 (intermediário/grau moderado ou moderadamente diferenciado), em que as células cancerosas não se parecem com as células normais e crescem um pouco mais rápido do que as células normais; e grau 3 (alto grau ou pouco diferenciado), em que células cancerosas são muito diferentes das células normais e são de progressão rápida (BREASTCANCER.ORG, 2010).

Pacientes portadoras do câncer de mama em vulnerabilidade extrema encontram-se em um momento de intensa fragilidade física e emocional. Diante de tal quadro, os cuidados paliativos tornam-se uma estratégia de cuidado essencial para proporcionar uma melhor qualidade de vida a estas pacientes. A Organização Mundial da Saúde (OMS) define cuidados paliativos como cuidados ativos e totais promovidos por uma equipe de saúde multidisciplinar que objetiva melhorar a qualidade de vida da pessoa e dos seus familiares diante de uma doença que ameace a vida. Tais cuidados são realizados por meio da prevenção e do alívio do sofrimento e da dor, bem como de outros problemas físicos, sociais, psicológicos e espirituais (SILVA et al., 2015).

No Brasil, foi estimada para o ano de 2015 a ocorrência de 57.120 novos casos de câncer de mama, com um risco estimado de 56,09 casos a cada 100 mil mulheres. Nesse contexto, a mortalidade mostra-se crescente, o que pode ser atribuído ao retardo no diagnóstico e ao atraso na instituição de terapêutica adequada, o que propicia o crescimento tumoral, tornando o prognóstico da população vulnerável tardio (INSTITUTO NACIONAL DE CÂNCER, 2015).

Diante da relevância dos cuidados paliativos para a assistência à mulher portadora de câncer de mama em vulnerabilidade extrema, esta pesquisa foi desenvolvida com o intuito de refletir sobre uma forma de cuidado mais integral e humanizado para aquelas pessoas acometidas por doenças terminais.

Dentre inúmeras discussões sobre o assunto no decorrer do curso de enfermagem, envolvendo a identificação de um cenário preocupante apontado pelas 
estatísticas oficiais, bem como a observação in loco do grande contingente de mulheres brasileiras doentes atendidas em hospital oncológico, em função de adoecimento ocasionado por neoplasia maligna da mama, foram suscitados diversos questionamentos sobre o tema. Nestes predominaram as indagações sobre a possibilidade de o câncer de mama afetar a qualidade de vida da mulher brasileira e sobre modos de atingir um adequado desempenho enquanto profissional enfermeiro no enfrentamento deste quadro.

Dentro deste contexto, a pesquisa tem como objetivo identificar o perfil das mulheres com câncer de mama em vulnerabilidade extrema e indicar o que dizem os estudos na literatura nacional sobre os cuidados paliativos realizados pelo enfermeiro a essas mulheres.

Nesse entendimento, as autoras se propõem a responder tal objetivo por meio de uma revisão integrativa. $\bigcirc$ estudo tem $\mathrm{O}$ intuito de contribuir com a ciência em saúde e nortear futuras pesquisas nas quais autores inquietar-se-ão sobre a possibilidade de planejar medidas humanizadas para minimizar o sofrimento do paciente portador de câncer de mama em vulnerabilidade extrema e seus familiares.

\section{METODOLOGIA}

Trata-se de uma revisão integrativa de literatura, que é uma forma de investigar estudos já publicados, visando a obter conclusões a respeito de um tópico particular. É considerada uma estratégia utilizada para identificar as evidências existentes, fundamentando a prática de saúde nas diferentes especialidades (WHITEMORE; KNAF, 2005).

Neste contexto, a revisão integrativa oferece aos profissionais de diversas áreas de atuação na saúde o acesso rápido aos resultados relevantes de pesquisas que fundamentam as condutas ou a tomada de decisão, proporcionando um saber crítico. Desse modo, cabe-nos compreender que a síntese dos resultados de pesquisas relevantes é reconhecida mundialmente porque facilita a incorporação de evidências, ou seja, agiliza a transferência de conhecimento novo para a prática (MENDES; SILVEIRA; GALVÃO, 2008). Em consonância com Whitemore e Knaf (2005) e Mendes, Silveira e Galvão (2008), foram adotados os seguintes procedimentos metodológicos:

1. Escolha da pergunta de pesquisa;

2. Definição dos critérios de inclusão e exclusão dos estudos;

3. Seleção da amostra;

4. Inclusão dos estudos selecionados em formato de tabela construída a partir do Microsoft Word;

5. Análise dos resultados, identificando semelhanças, diferenças e conflitos;

6. Discussão e análise dos resultados;

7. Apresentação do estudo em forma de artigo científico.

Como questão norteadora adotou-se: "Qual a importância dos cuidados paliativos a pacientes com câncer de mama em vulnerabilidade extrema"?

Para a seleção dos artigos foram utilizadas as bases de dados: Scientific Electronic Library Online - SciELO e Literatura LatinoAmericana e do Caribe em Ciências da Saúde - LILACS.

Os critérios de inclusão definidos foram: a) Trabalhos publicados no formato de artigos científicos completos e artigos originais; b) Estudos que continham os descritores listados neste projeto, no resumo e/ou no título e publicados no idioma português, sendo publicados entre 2010 a 2015, na forma completa pelo acesso via Biblioteca Virtual em Saúde (BVS); c) Trabalhos cujo objetivo refere-se explicitamente ao objeto de estudo. 
Os critérios de exclusão foram: a) Publicações na forma de cartas, resenhas e editoriais; b) Publicações do tipo: livros, capítulos de livros e boletins informativos; c) Estudos que não estão disponibilizados online na íntegra para análise; d) Estudos duplicados; e) Estudos fora do tema; f) Teses e dissertações.

Para a análise e posterior síntese dos artigos que atenderam aos critérios de inclusão, definem-se os seguintes aspectos na SciELO e LILACS: coleções do Brasil; idioma em português; ano de publicação entre 2010-2015.

Em uma primeira etapa, foram usados para o levantamento dos artigos os seguintes descritores de assunto: "Câncer de mama", "Saúde da mulher" e "Enfermeiro". Em seguida, realizou-se busca ativa na base de dados SciELO.

Na busca realizada ao primeiro DeCS, "Câncer de mama" foi cadastrado 1 vez por palavras e termos; para este DeCS foram encontrados na base de dados SciELO 1.692 textos disponíveis. Na busca realizada ao segundo DeCS, "Saúde da mulher" foi cadastrado 1 vez por palavras e termos; na busca realizada na base de dados SciELO foram encontrados 936 textos disponíveis. Na busca realizada ao terceiro DeCS, "Enfermeiro" foi cadastrado 7 vezes por palavras e termos; na busca realizada na base de dados SciELO foram encontrados 1.419 textos disponíveis.

Posteriormente, realizou-se o primeiro refinamento, contemplando os seguintes aspectos: coleções: Brasil; idioma: português; ano de publicação: 2010-2015. No primeiro refinamento para DeCS "Câncer de mama", a SciELO selecionou 258 textos disponíveis. No primeiro refinamento para DeCS "Saúde da mulher", a SciELO selecionou 322 textos disponíveis. Já no primeiro refinamento para DeCS "Enfermeiro", a SciELO selecionou 532 textos disponíveis.

$\mathrm{Na}$ busca realizada ao primeiro DeCS, "Câncer de mama", foram encontrados na base de dados LILACS 6.367 textos disponíveis. Para o segundo DeCS, "Saúde da mulher", foram encontrados 7.096 textos disponíveis. Para o terceiro DeCS, "Enfermeiro", foram encontrados 4.471 textos disponíveis. Posteriormente, realizou-se o primeiro refinamento, contemplando os seguintes aspectos: país de filiação: Brasil; idioma: português; ano de publicação: 2010-2015 para os três DeCS. No primeiro refinamento para DeCS "Câncer de mama", a LILACS selecionou 479 textos disponíveis, enquanto que para DeCS "Saúde da mulher" a LILACS selecionou 32 textos disponíveis e para DeCS "Enfermeiro" a LILACS selecionou 1.065 textos disponíveis.

A amostra final resultou em artigos que atenderam aos critérios de inclusão temporal, ou seja, publicados entre 2010 e 2015. Quanto aos tipos de estudo presentes entre os artigos selecionados, tem-se: cinco artigos originais; cinco artigos de pesquisa; e dois artigos de revisão. De acordo com os desenhos metodológicos, os tipos de pesquisas investigados foram: sete artigos de pesquisa qualitativa descritiva exploratória, um estudo quantitativo, três artigos de revisão e um estudo transversal.

Observou-se que, quanto ao método de estudo, há prevalência de pesquisa qualitativa e estudos transversais. De acordo com Boaventura (2009), a pesquisa descritiva exploratória é uma investigação que visa proporcionar maior familiaridade com o problema, permitindo constituir hipóteses por meio de levantamento bibliográfico ou entrevistas com pessoas que têm participação com o problema. Sendo classificada como qualitativa em virtude da análise dos resultados que é realizada com base na literatura consultada, estabelecem-se concordâncias e discordâncias ou comparações e interpretações.

Os estudos transversais descrevem uma situação ou fenômeno em um momento não definido. Seu modelo apresenta-se como uma fotografia ou recorte instantâneo que se faz numa população por meio de uma amostragem, examinando-se, nos 
integrantes da casuística ou amostra, a presença ou ausência da exposição e a presença ou ausência do efeito (ou doença) (HOCHMAN et al., 2005).

\begin{tabular}{|c|l|l|}
\hline Id & \multicolumn{1}{|c|}{ Tipos de pesquisa } & \multicolumn{1}{|c|}{ Instrumento de intervenção/coleta de dados } \\
\hline A & Pesquisa Quantiqualitativa & Entrevistas semiestruturadas e questionário \\
\hline B & Pesquisa qualitativa descritiva & Entrevistas semiestruturadas \\
\hline C & Estudo transversal & $\begin{array}{l}\text { Escala de Rosenberg para autoestima e o WHOQOL-bref } \\
\text { para a qualidade de vida }\end{array}$ \\
\hline D & Pesquisa qualitativa & Revisão da literatura \\
\hline E & Pesquisa qualitativa & Entrevista semiestruturada \\
\hline F & Pesquisa qualitativa & Entrevista semiestruturada \\
\hline G & Pesquisa qualitativa & Revisão da literatura \\
\hline H & $\begin{array}{l}\text { Pesquisa qualitativa exploratória, descritiva, } \\
\text { retrospectiva }\end{array}$ & Revisão da literatura \\
\hline I & Pesquisa qualitativa & Entrevistas semiestruturadas \\
\hline J & Pesquisa qualitativa & Entrevistas semiestruturadas \\
\hline K & Pesquisa qualitativa & Entrevista semiestruturada \\
\hline L & Pesquisa qualitativa & Entrevista semiestruturada \\
\hline & & endos conformetipo de \\
\hline
\end{tabular}

Quadro 1 - Artigos científicos agrupados conforme tipo de pesquisa

Fonte: Dados da pesquisa. Elaboração própria (2016).

\section{RESULTADOS E DISCUSSÃO}

Com o cruzamento dos descritores, conforme descrito na metodologia, foram encontrados 32 artigos nas fontes de dados e, após a submissão destes aos critérios de inclusão e exclusão da investigação, foram obtidos 25 estudos. Quando analisados de forma criteriosa, foi visto que apenas 12 respondiam aos objetivos e à questão norteadora do estudo, sendo estes então colocados na amostra final.

Dos artigos pesquisados, todos foram produções nacionais divulgados em revistas brasileiras, com prevalência de estudos realizados na região Sudeste (São Paulo, Rio de Janeiro e Minas Gerais), Nordeste (Paraíba e
Bahia) e Sul (Santa Catarina). Os autores dos artigos selecionados são profissionais da área de Enfermagem, Psicologia e Medicina, com atuação no âmbito hospitalar e educacional - como pesquisadores ligados a Programas de Pós-Graduação (Mestrado e Doutorado) na área da Saúde (Enfermagem, Saúde Pública e Ciências da Saúde).

No quadro sinóptico descritivo 2, os artigos estão agrupados a partir de título do artigo, autor, objetivo, resultados e recomendações/conclusão. Os artigos estudados foram categoricamente identificados por letras do alfabeto ( $A$ a $L$ ), com o intuito de viabilizar de forma sucinta e clara suas exposições, o que atuou como instrumento facilitador da análise. 


\begin{tabular}{|c|c|c|c|c|c|c|}
\hline Id & Ano & $\begin{array}{c}\text { Título } \\
\text { do artigo }\end{array}$ & Autor & Objetivo & Resultado & $\begin{array}{l}\text { Recomendações/ } \\
\text { Conclusão }\end{array}$ \\
\hline A & 2015 & $\begin{array}{l}\text { Cuidados } \\
\text { paliativos: } \\
\text { desafios para } \\
\text { cuidadores e } \\
\text { profissionais de } \\
\text { saúde }\end{array}$ & $\begin{array}{l}\text { ALVES. Railda } \\
\text { Fernandes; } \\
\text { ANDRADE, Samkya } \\
\text { Fernandes de } \\
\text { Oliveira; MELO, } \\
\text { Myriam Oliveira, Kílvia } \\
\text { Barbosa Cavalcante; } \\
\text { ANGELIM, Raquel } \\
\text { Medeiros }\end{array}$ & $\begin{array}{l}\text { Conhecer os } \\
\text { discursos e as } \\
\text { práticas sobre } \\
\text { os } C P, \text { e as } \\
\text { dificuldades } \\
\text { no exercício } \\
\text { desses cuidados. } \\
\text { O método foi } \\
\text { quantiqualitativo. }\end{array}$ & $\begin{array}{l}\text { A análise dos } \\
\text { discursos mostrou } \\
\text { que os CP são } \\
\text { entendidos como } \\
\text { práticas voltadas } \\
\text { ao alívio da dor, ao } \\
\text { amparo à família do } \\
\text { paciente e ao uso } \\
\text { de medicamentos. }\end{array}$ & $\begin{array}{l}\text { Existem dúvidas } \\
\text { quanto aos fazeres } \\
\text { do psicólogo nos } \\
\text { CP, ainda que sejam } \\
\text { efetuadas práticas } \\
\text { correlatas. Este } \\
\text { estudo foi relevante } \\
\text { porque poderá } \\
\text { indicar políticas } \\
\text { públicas voltadas } \\
\text { à promoção da } \\
\text { qualidade de vida } \\
\text { de pessoas com } \\
\text { doenças terminais. }\end{array}$ \\
\hline B & 2015 & $\begin{array}{l}\text { Cuidados } \\
\text { paliativos na } \\
\text { assistência } \\
\text { de alta } \\
\text { complexidade } \\
\text { em oncologia: } \\
\text { percepção de } \\
\text { enfermeiros }\end{array}$ & $\begin{array}{l}\text { SILVA Marcelle } \\
\text { Miranda da; } \\
\text { SANTANDA, Nathália } \\
\text { Gabriella Meliano } \\
\text { de; SANTOS, } \\
\text { Monique Casartelli; } \\
\text { CIRILO, Juliana Dias; } \\
\text { BARROCAS, Desirée } \\
\text { Lessa Rodrigues; } \\
\text { MOREIRA, Marléa } \\
\text { Chagas. }\end{array}$ & $\begin{array}{l}\text { Identificar as } \\
\text { dificuldades } \\
\text { enfrentadas } \\
\text { na prestação } \\
\text { da assistência } \\
\text { à pessoa } \\
\text { hospitalizada } \\
\text { no contexto dos } \\
\text { cuidados paliativos } \\
\text { em um Centro de } \\
\text { Assistência de Alta } \\
\text { Complexidade } \\
\text { em Oncologia } \\
\text { do estado do } \\
\text { Rio de Janeiro, } \\
\text { na percepção } \\
\text { dos enfermeiros; } \\
\text { e discutir } \\
\text { estratégias para } \\
\text { melhor qualificar } \\
\text { a assistência de } \\
\text { enfermagem nesse } \\
\text { contexto. }\end{array}$ & $\begin{array}{l}\text { Emergiram duas } \\
\text { categorias: o } \\
\text { lidar cotidiano } \\
\text { do enfermeiro } \\
\text { na presença } \\
\text { de pessoas } \\
\text { hospitalizadas em } \\
\text { cuidados paliativos } \\
\text { oncológicos; } \\
\text { e o pensar em } \\
\text { estratégias para } \\
\text { melhor qualificar } \\
\text { a assistência de } \\
\text { enfermagem. } \\
\text { Destacam-se a falta } \\
\text { de conhecimento } \\
\text { em cuidados } \\
\text { paliativos; a } \\
\text { necessária } \\
\text { criação de leitos } \\
\text { diferenciados; e } \\
\text { formação de redes } \\
\text { institucionais. }\end{array}$ & $\begin{array}{l}\text { O estudo } \\
\text { alerta sobre a } \\
\text { necessidade de } \\
\text { novas pesquisas, } \\
\text { assim como de } \\
\text { mudanças efetivas } \\
\text { para atendimento } \\
\text { dessas pessoas, } \\
\text { salientando } \\
\text { também que } \\
\text { as estratégias } \\
\text { de assistência } \\
\text { dependem de } \\
\text { esforço coletivo } \\
\text { para qualificar a } \\
\text { prática. }\end{array}$ \\
\hline C & 2015 & $\begin{array}{l}\text { Autoestima e } \\
\text { qualidade de } \\
\text { vida de mulheres } \\
\text { submetidas } \\
\text { à cirurgia } \\
\text { oncológica de } \\
\text { mama }\end{array}$ & $\begin{array}{l}\text { GOMES, Nathália } \\
\text { Silva; } \\
\text { SOARES, Maurícia } \\
\text { Brochado Oliveira; } \\
\text { SILVA, Sueli Riul da }\end{array}$ & $\begin{array}{l}\text { Analisar a } \\
\text { influência } \\
\text { das variáveis } \\
\text { sociodemográficas } \\
\text { e clínicas, } \\
\text { bem como da } \\
\text { autoestima na } \\
\text { qualidade de } \\
\text { vida de mulheres } \\
\text { submetidas à } \\
\text { cirurgia oncológica } \\
\text { de mama. }\end{array}$ & $\begin{array}{l}\text { Observou-se } \\
\text { correlação: } \\
\text { moderada e } \\
\text { positiva entre } \\
\text { a autoestima e } \\
\text { a escolaridade; } \\
\text { positiva e } \\
\text { moderada entre o } \\
\text { domínio social e } \\
\text { a renda familiar e } \\
\text { entre o ambiental e } \\
\text { a idade; moderada } \\
\text { entre a autoestima } \\
\text { e o domínio } \\
\text { ambiental; e forte } \\
\text { entre a autoestima } \\
\text { e os domínios físico } \\
\text { e psicológico. }\end{array}$ & $\begin{array}{l}\text { A implementação } \\
\text { de propostas de } \\
\text { enfermagem, como } \\
\text { a formação de } \\
\text { grupos que visem } \\
\text { à manutenção de } \\
\text { alta autoestima e } \\
\text { ofereçam suporte } \\
\text { àquelas com } \\
\text { necessidades ainda } \\
\text { a serem atendidas, } \\
\text { visto que a } \\
\text { reabilitação física e } \\
\text { psicossocial não se } \\
\text { esgota com o fim } \\
\text { dos procedimentos } \\
\text { cirúrgicos. }\end{array}$ \\
\hline
\end{tabular}




\begin{tabular}{|c|c|c|c|c|c|c|}
\hline Id & Ano & $\begin{array}{c}\text { Título } \\
\text { do artigo }\end{array}$ & Autor & Objetivo & Resultado & $\begin{array}{l}\text { Recomendações/ } \\
\text { Conclusão }\end{array}$ \\
\hline D & 2015 & $\begin{array}{l}\text { Cuidados } \\
\text { paliativos no } \\
\text { câncer e os } \\
\text { princípios } \\
\text { doutrinários do } \\
\text { SUS }\end{array}$ & $\begin{array}{l}\text { MENDES } \\
\text { Ernani Costa; } \\
\text { VASCONCELLOS, Luiz } \\
\text { Carlos Fadel de. }\end{array}$ & $\begin{array}{l}\text { Fazer uma } \\
\text { reflexão sobre } \\
\text { a cobertura da } \\
\text { população, e sobre } \\
\text { a organização } \\
\text { desta cobertura } \\
\text { na atenção básica, } \\
\text { assim como na } \\
\text { de média e alta } \\
\text { complexidades, } \\
\text { abrangendo } \\
\text { também a } \\
\text { formação de } \\
\text { profissionais, a } \\
\text { partir de revisão } \\
\text { bibliográfica e dos } \\
\text { instrumentos. }\end{array}$ & $\begin{array}{l}\text { A prática em } \\
\text { cuidados paliativos } \\
\text { tende a crescer. } \\
\text { Essa realidade vai } \\
\text { exigir uma resposta } \\
\text { mais qualificada } \\
\text { da política de } \\
\text { saúde brasileira, } \\
\text { necessitando } \\
\text { estar ancorada } \\
\text { numa perspectiva } \\
\text { de apoio global } \\
\text { aos múltiplos } \\
\text { problemas dos } \\
\text { pacientes que se } \\
\text { encontram na fase } \\
\text { mais avançada da } \\
\text { doença e no final } \\
\text { da vida. }\end{array}$ & $\begin{array}{l}\text { Conclui-se que a } \\
\text { estruturação da } \\
\text { rede de cuidados } \\
\text { paliativos carece de } \\
\text { eficácia para o seu } \\
\text { desenvolvimento, } \\
\text { enquanto política } \\
\text { pública coerente } \\
\text { com a doutrina do } \\
\text { SUS. }\end{array}$ \\
\hline $\mathrm{E}$ & 2014 & $\begin{array}{l}\text { Enfermeiras no } \\
\text { atendimento } \\
\text { ambulatorial } \\
\text { a mulheres } \\
\text { com feridas } \\
\text { neoplásicas } \\
\text { malignas nas } \\
\text { mamas }\end{array}$ & $\begin{array}{l}\text { FIRMINO, Flávia, } \\
\text { ALCÂNTARA, Laísa } \\
\text { Figueiredo Ferreira } \\
\text { Lós }\end{array}$ & $\begin{array}{l}\text { Analisar relatos } \\
\text { de enfermeiros } \\
\text { que realizam } \\
\text { curativos em } \\
\text { feridas neoplásicas } \\
\text { de mulheres } \\
\text { acometidas } \\
\text { pelo câncer de } \\
\text { mama e traçar } \\
\text { contribuiçóes para } \\
\text { a assistência de } \\
\text { enfermagem. }\end{array}$ & $\begin{array}{l}\text { Ser enfermeira } \\
\text { oncologista } \\
\text { foi apontado } \\
\text { como requisito } \\
\text { que qualifica a } \\
\text { prática no cuidar } \\
\text { de mulheres } \\
\text { acometidas pelo } \\
\text { câncer de mama } \\
\text { e com ferida } \\
\text { neoplásica maligna } \\
\text { decorrente. } \\
\text { Os cuidados } \\
\text { profissional- } \\
\text { técnico e afetivo, } \\
\text { associados ao } \\
\text { conforto ambiental } \\
\text { e a espaços para } \\
\text { expressão dos } \\
\text { sentimentos e } \\
\text { para comunicação, } \\
\text { são aç̃̃es que } \\
\text { contribuem para } \\
\text { o vínculo entre } \\
\text { profissionais de } \\
\text { saúde e seus } \\
\text { pacientes. }\end{array}$ & $\begin{array}{l}\text { Há necessidade } \\
\text { de conhecimentos } \\
\text { específicos na área } \\
\text { da enfermagem } \\
\text { oncológica, } \\
\text { envolvimento } \\
\text { profissional, } \\
\text { habilidade técnica } \\
\text { e autonomia, } \\
\text { realização de } \\
\text { grupo terapêutico, } \\
\text { atendimento } \\
\text { clínico em interface } \\
\text { com abordagem } \\
\text { paliativa, e trabalho } \\
\text { colaborativo em } \\
\text { equipe. }\end{array}$ \\
\hline$F$ & 2010 & $\begin{array}{l}\text { Estratégias de } \\
\text { enfrentamento } \\
\text { do câncer de } \\
\text { mama: um } \\
\text { estudo de caso } \\
\text { com famílias } \\
\text { de mulheres } \\
\text { mastectomizadas }\end{array}$ & $\begin{array}{l}\text { TAVARES, Jeane } \\
\text { Saskya Campos; } \\
\text { TRAD, Leny Alves } \\
\text { Bonfim }\end{array}$ & $\begin{array}{l}\text { Conhecer } \\
\text { e analisar } \\
\text { estratégias de } \\
\text { enfrentamento do } \\
\text { câncer de mama } \\
\text { desenvolvidas } \\
\text { por famílias que } \\
\text { têm entre seus } \\
\text { membros mulheres } \\
\text { com esta doença. }\end{array}$ & $\begin{array}{l}\text { Destacou-se } \\
\text { no processo de } \\
\text { enfrentamento do } \\
\text { câncer a relação } \\
\text { dialética entre } \\
\text { as estratégias } \\
\text { de pacientes } \\
\text { e familiares, a } \\
\text { participação ativa } \\
\text { e constante dos } \\
\text { membros das } \\
\text { famílias de origem } \\
\text { e extensa e as } \\
\text { características da } \\
\text { instituição em que } \\
\text { as mulheres com } \\
\text { câncer de mama } \\
\text { foram atendidas. }\end{array}$ & $\begin{array}{l}\text { A adoção de } \\
\text { estratégias de } \\
\text { enfrentamento } \\
\text { adequadas é um } \\
\text { dos fatores que } \\
\text { contribuem para a } \\
\text { qualidade de vida } \\
\text { de pacientes e } \\
\text { familiares. }\end{array}$ \\
\hline
\end{tabular}




\begin{tabular}{|c|c|c|c|c|c|c|}
\hline Id & Ano & $\begin{array}{c}\text { Título } \\
\text { do artigo }\end{array}$ & Autor & Objetivo & Resultado & $\begin{array}{l}\text { Recomendações/ } \\
\text { Conclusão }\end{array}$ \\
\hline G & 2010 & $\begin{array}{l}\text { Hormonioterapia } \\
\text { paliativa em } \\
\text { câncer de mama: } \\
\text { aspectos práticos } \\
\text { e revisão da } \\
\text { literatura. }\end{array}$ & $\begin{array}{l}\text { LEAL, Jorge Henrique } \\
\text { Santos; CUBERO } \\
\text { Daniel; DEL GIGLIO, } \\
\text { Auro. }\end{array}$ & $\begin{array}{l}\text { Revisar a literatura } \\
\text { relacionada à } \\
\text { hormonioterapia } \\
\text { no tratamento do } \\
\text { câncer de mama } \\
\text { avançado, com } \\
\text { ênfase nos ensaios } \\
\text { clínicos com } \\
\text { maior impacto } \\
\text { científico, além } \\
\text { de contextualizar } \\
\text { estes estudos com } \\
\text { a prática clínica } \\
\text { diária. }\end{array}$ & $\begin{array}{l}\text { Dentre os } \\
\text { diversos tipos } \\
\text { de tratamento, a } \\
\text { hormonioterapia } \\
\text { tem papel } \\
\text { fundamental, pois } \\
\text { tem bom perfil } \\
\text { de toxicidade, } \\
\text { elevada eficácia e } \\
\text { diversas opções } \\
\text { terapêuticas. }\end{array}$ & $\begin{array}{l}\text { A hormonioterapia } \\
\text { é um recurso } \\
\text { altamente eficaz } \\
\text { para o tratamento } \\
\text { paliativo do câncer } \\
\text { de mama e seu } \\
\text { uso mais difundido } \\
\text { será certamente } \\
\text { encontrado por } \\
\text { clínicos gerais que } \\
\text { participem do } \\
\text { cuidado destas } \\
\text { pacientes }\end{array}$ \\
\hline $\mathrm{H}$ & 2012 & $\begin{array}{l}\text { Atenção paliativa } \\
\text { oncológica em } \\
\text { unidade de } \\
\text { terapia intensiva: } \\
\text { um estudo } \\
\text { da produção } \\
\text { científica da } \\
\text { enfermagem }\end{array}$ & $\begin{array}{l}\text { MENDONÇA, Ana } \\
\text { Carolina Abeid; } \\
\text { MOREIRA, Marléa } \\
\text { Chagas; CARVALHO, } \\
\text { Vilma de }\end{array}$ & $\begin{array}{l}\text { Analisar a } \\
\text { produção científica } \\
\text { da enfermagem na } \\
\text { atenção paliativa } \\
\text { oncológica em } \\
\text { unidades de } \\
\text { terapia intensiva. }\end{array}$ & $\begin{array}{l}\text { Análise dos temas } \\
\text { focalizados indica } \\
\text { a apreensão do } \\
\text { fenômeno na esfera } \\
\text { subjetiva, na ótica } \\
\text { dos enfermeiros } \\
\text { como sujeitos/ } \\
\text { consciência do } \\
\text { conhecimento } \\
\text { para apreensão } \\
\text { de situações de } \\
\text { enfermagem } \\
\text { relacionadas às } \\
\text { estratégias e } \\
\text { aos obstáculos à } \\
\text { implantação da } \\
\text { atenção paliativa } \\
\text { oncológica } \\
\text { nesse cenário, } \\
\text { destacando-se } \\
\text { também } \\
\text { contribuições da } \\
\text { atenção paliativa } \\
\text { oncológica para } \\
\text { clientes e familiares. }\end{array}$ & $\begin{array}{l}\text { As repercussões } \\
\text { demonstradas } \\
\text { nos aspectos } \\
\text { epistemológicos } \\
\text { destacados } \\
\text { possibilitam afirmar } \\
\text { que a assistência } \\
\text { de enfermagem } \\
\text { a pessoas com } \\
\text { câncer avançado } \\
\text { sem possibilidades } \\
\text { de cura na Unidade } \\
\text { de Terapia Intensiva } \\
\text { é permeada } \\
\text { por desafios } \\
\text { que requerem } \\
\text { investigações a } \\
\text { fim de subsidiar } \\
\text { critérios e } \\
\text { estratégias para } \\
\text { atuação da equipe } \\
\text { de enfermagem } \\
\text { para essa clientela. }\end{array}$ \\
\hline I & 2012 & $\begin{array}{l}\text { Prática } \\
\text { profissional de } \\
\text { enfermeiras } \\
\text { que cuidam } \\
\text { de pacientes } \\
\text { com câncer em } \\
\text { hospitais gerais }\end{array}$ & $\begin{array}{l}\text { SILVA, Josiane } \\
\text { Travençolo da; } \\
\text { CASSULI, Maria Clara } \\
\text { Matheus; FUSTINONI, } \\
\text { Suzete Maria; } \\
\text { GUTIÉRREZ Maria } \\
\text { Gaby Rivero de. }\end{array}$ & $\begin{array}{l}\text { Compreender o } \\
\text { típico da prática } \\
\text { profissional de } \\
\text { enfermeiras } \\
\text { que cuidam } \\
\text { de pacientes } \\
\text { com câncer em } \\
\text { hospitais gerais, } \\
\text { com intuito de } \\
\text { descobrir os } \\
\text { motivos que } \\
\text { impulsionam } \\
\text { a ação desses } \\
\text { profissionais } \\
\text { e colocar em } \\
\text { evidência o que } \\
\text { há de original, } \\
\text { significativo, } \\
\text { específico e típico } \\
\text { nesse fenômeno }\end{array}$ & $\begin{array}{l}\text { Os dados } \\
\text { obtidos por meio } \\
\text { da entrevista } \\
\text { semiestruturada } \\
\text { mostraram que } \\
\text { as enfermeiras } \\
\text { reconhecem } \\
\text { não possuir o } \\
\text { conhecimento } \\
\text { teórico necessário } \\
\text { e a experiência ou } \\
\text { prática suficientes } \\
\text { para cuidar de } \\
\text { pacientes com } \\
\text { câncer. }\end{array}$ & $\begin{array}{l}\text { As instituições } \\
\text { hospitalares } \\
\text { deveriam promover } \\
\text { capacitação em } \\
\text { serviço, com a } \\
\text { abordagem de } \\
\text { temas relacionados } \\
\text { ao atendimento } \\
\text { ao paciente com } \\
\text { câncer, a fim } \\
\text { de promover } \\
\text { aperfeiçoamento } \\
\text { profissional e, } \\
\text { consequentemente, } \\
\text { melhoria da } \\
\text { assistência. }\end{array}$ \\
\hline
\end{tabular}




\begin{tabular}{|c|c|c|c|c|c|c|}
\hline Id & Ano & $\begin{array}{l}\text { Título } \\
\text { do artigo }\end{array}$ & Autor & Objetivo & Resultado & $\begin{array}{l}\text { Recomendações/ } \\
\text { Conclusão }\end{array}$ \\
\hline $\mathbf{J}$ & 2012 & $\begin{array}{l}\text { Itinerário } \\
\text { terapêutico no } \\
\text { câncer de mama: } \\
\text { uma contribuição } \\
\text { para o cuidado } \\
\text { de enfermagem }\end{array}$ & $\begin{array}{l}\text { ROSA Luciana Martins } \\
\text { da; RADÜNZI, Vera }\end{array}$ & $\begin{array}{l}\text { Conhecer } \\
\text { o itinerário } \\
\text { terapêutico } \\
\text { adotado pela } \\
\text { mulher com câncer } \\
\text { de mama. }\end{array}$ & $\begin{array}{l}\text { Os cuidados que } \\
\text { compõem estas } \\
\text { subcategorias } \\
\text { representam } \\
\text { cuidados } \\
\text { significantes para a } \\
\text { mulher com câncer } \\
\text { de mama e devem } \\
\text { ser incluídos no } \\
\text { plano de cuidado } \\
\text { de enfermagem } \\
\text { e de outros } \\
\text { profissionais da } \\
\text { área da saúde. }\end{array}$ & $\begin{array}{l}\text { O conhecimento } \\
\text { do itinerário } \\
\text { terapêutico das } \\
\text { mulheres com } \\
\text { câncer de mama } \\
\text { configura um saber } \\
\text { orientador para } \\
\text { o planejamento } \\
\text { dos cuidados de } \\
\text { enfermagem e das } \\
\text { ações na área da } \\
\text { saúde. }\end{array}$ \\
\hline K & 2012 & $\begin{array}{l}\text { Análise das } \\
\text { respostas } \\
\text { comportamentais } \\
\text { ao câncer de } \\
\text { mama utilizando } \\
\text { o modelo } \\
\text { adaptativo de } \\
\text { Roy }\end{array}$ & $\begin{array}{l}\text { SANTOS, Letícia Rosa; } \\
\text { TAVARES, Glaucia } \\
\text { Batista; REIS, Paula } \\
\text { Elaine Diniz dos. }\end{array}$ & $\begin{array}{l}\text { Analisar as } \\
\text { respostas } \\
\text { comportamentais } \\
\text { das mulheres } \\
\text { durante o } \\
\text { tratamento } \\
\text { do câncer de } \\
\text { mama utilizando } \\
\text { o Modelo de } \\
\text { Adaptação de Roy }\end{array}$ & $\begin{array}{l}\text { Estudos } \\
\text { demonstram que } \\
\text { o câncer e sua } \\
\text { terapêutica podem } \\
\text { gerar estímulos } \\
\text { que irão interferir } \\
\text { na sexualidade. } \\
\text { Conhecer os } \\
\text { mecanismos de } \\
\text { enfrentamento } \\
\text { destas mulheres } \\
\text { deve ser uma } \\
\text { preocupação dos } \\
\text { profissionais que } \\
\text { prestam assistência, } \\
\text { para que se possa } \\
\text { oferecer o cuidado } \\
\text { integral. }\end{array}$ & $\begin{array}{l}\text { Conclui-se que } \\
\text { a utilização } \\
\text { do modelo de } \\
\text { adaptação de Roy } \\
\text { foi apropriada, pois } \\
\text { permitiu apreender } \\
\text { as alterações } \\
\text { relacionadas aos } \\
\text { modos adaptativos } \\
\text { e visualizar de } \\
\text { forma concreta } \\
\text { quais os focos para } \\
\text { as intervenções de } \\
\text { enfermagem. }\end{array}$ \\
\hline L & 2013 & $\begin{array}{l}\text { Análise da } \\
\text { comunicação } \\
\text { acerca da } \\
\text { sexualidade, } \\
\text { estabelecida } \\
\text { pelas } \\
\text { enfermeiras, } \\
\text { com pacientes } \\
\text { no contexto } \\
\text { assistencial do } \\
\text { câncer de mama }\end{array}$ & $\begin{array}{l}\text { JUNQUEIRA, Lilian } \\
\text { Cláudia Ulian; GIAMI, } \\
\text { Elisabeth Meloni } \\
\text { Vieira; SANTOS, Alain } \\
\text { Manoel Antônio dos. }\end{array}$ & $\begin{array}{l}\text { Investigar como } \\
\text { se desenvolve } \\
\text { a comunicação } \\
\text { acerca da } \\
\text { sexualidade, } \\
\text { estabelecida } \\
\text { pela enfermeira, } \\
\text { no contexto do } \\
\text { cuidado em saúde } \\
\text { para as } \\
\text { mulheres } \\
\text { mastectomizadas. } \\
\text { Analisar o modo } \\
\text { como a enfermeira } \\
\text { oferece sua escuta } \\
\text { e presta cuidados } \\
\text { à } \\
\text { mulher com } \\
\text { câncer de mama, } \\
\text { especialmente } \\
\text { acerca de sua } \\
\text { sexualidade, de } \\
\text { forma a suscitar } \\
\text { novos } \\
\text { conhecimentos } \\
\text { acerca da interface } \\
\text { entre sexualidade } \\
\text { e cuidados em } \\
\text { oncologia. }\end{array}$ & $\begin{array}{l}\text { O cuidado é } \\
\text { suprido pela } \\
\text { aplicação de uma } \\
\text { medida protocolar, } \\
\text { seguindo um guia } \\
\text { de instruções } \\
\text { previamente } \\
\text { elaborado no } \\
\text { serviço, um manual } \\
\text { de recomendações } \\
\text { práticas ou mesmo } \\
\text { uma lista de } \\
\text { orientações gerais. }\end{array}$ & $\begin{array}{l}\text { O cuidado em } \\
\text { enfermagem } \\
\text { deve incluir o } \\
\text { acolhimento de } \\
\text { todos os elementos } \\
\text { que apresentem } \\
\text { relação com a } \\
\text { vivência da mulher, } \\
\text { inclusive no que } \\
\text { se refere à sua } \\
\text { sexualidade. }\end{array}$ \\
\hline
\end{tabular}

Quadro 2 - Sinóptico Descritivo: Artigos científicos selecionados na investigação agrupados conforme ano de publicação, título, autor, objetivos, resultados e recomendações/conclusões.

Fonte: Dados da pesquisa. Elaboração própria (2016). 
Durante a pesquisa realizada na Biblioteca Virtual da Saúde (BVS), os artigos foram coletados no período entre os meses de janeiro e março e como resultado obteve-se: sete artigos na base de dados SciELO e cinco na base de dados da Lilacs com os descritores propostos, sendo todos eles do período determinado no estudo como critério de inclusão. Foram eliminados da lista de publicações 12 artigos que apareceram em duplicidade e não abordaram o tema com foco para o objetivo deste estudo.

O quadro sinóptico 3 abaixo representa o resultado de artigos pesquisados por base de dados, onde podemos perceber a abrangência dada ao tema estudado em cada base de pesquisa.

\begin{tabular}{|c|l|l|}
\hline Id & \multicolumn{1}{|c|}{ Periódico } & \multicolumn{1}{|c|}{ Base de pesquisa } \\
\hline A & Fractal: Revista de Psicologia & Scielo \\
\hline B & Esc Anna Nery & Scielo \\
\hline C & REME $\bullet$ Rev Min Enferm & Lilacs \\
\hline D & Saúde Debate & Scielo \\
\hline E & Rev Rene. & Lilacs \\
\hline F & Ciência \& Saúde Coletiva & Scielo \\
\hline G & Rev Bras Clin Med, & Lilacs \\
\hline H & Esc Anna Nery (impr.), & Scielo \\
\hline I & Rev Bras Enferm & Scielo \\
\hline J & Rev. enferm. UERJ & Lilacs \\
\hline K & Esc Anna Nery (impr.) & Scielo \\
\hline L & Interface - Comunic., Saude, Educ. & Lilacs \\
\hline
\end{tabular}

Quadro 3 - Sinóptico Descritivo: Artigos científicos agrupados conforme o periódico da publicação e a base de pesquisa. Fonte: Dados da pesquisa. Elaboração própria (2016).

\section{Temática dos artigos pesquisados referente aos cuidados paliativos}

Nas últimas décadas, as novas tecnologias passaram a fazer parte das atividades dos seres humanos, dando uma grande contribuição para o desenvolvimento do conhecimento na sociedade. Este mecanismo também passou a inovar o campo da disseminação do conhecimento científico, no qual houve muitas iniciativas na área da saúde com o desenvolvimento de bibliotecas virtuais que armazenam e disseminam o conhecimento científico submetidos nestas bases.

Quanto à temática abordada pelos pesquisadores estudados, percebeu-se que a abordagem do tema vem sendo intensificada em virtude da crescente taxa de mortalidade por esta patologia, tornando-se com isso fonte de pesquisa relevante para os profissionais de saúde. Tais conhecimentos serviram para elucidar medidas preventivas para esta patologia, bem como para conhecer as emoções e sentimentos das mulheres portadoras do câncer de mama e, a partir destes conhecimentos, poder propor formas de cuidados paliativos e prevenção direcionadas para este público-alvo.

Medidas preventivas e cuidadas em saúde devem ser enfatizadas nas pesquisas científicas para que sejam melhor disseminados e, com isso, possa haver maior conhecimento sobre a doença, com destaque para a importância deste conhecimento para a detecção precoce e, principalmente, para a prevenção.

$\mathrm{Na}$ pesquisa realizada nestes mecanismos de informação e conhecimento sobre a temática estudada - mulher portadora de câncer de mama com a abordagem direcionada para os cuidados paliativos dos profissionais de enfermagem - obteve-se 
nas bibliotecas virtuais resultados com os seguintes temas: câncer de mama; enfermagem oncológica; cuidados paliativos.

No gráfico 1, podemos observar os temas de forma mais específica, como também a frequência de sua abordagem nas bases de dados pesquisadas.

Temática dos artigos

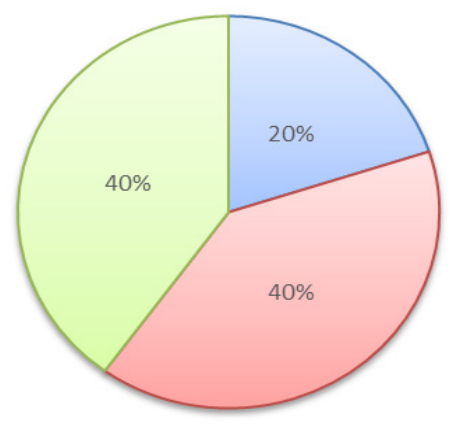

口Câncer de mama $\quad$ Enfermagem oncológica $\square$ Cuidados paliativos

Gráfico 1 - Temas abordados como objeto de estudo da pesquisa.

Fonte: Dados da pesquisa. Elaboração própria (2016).

\section{Temática dos artigos pesquisados em perfil das mulheres com câncer de mama}

- câncer de mama possui um índice que continua em elevação a cada ano, e a gravidade da doença, ainda diagnosticada tardiamente em mais da metade dos casos, representa uma situação desafiadora e carente de mudanças, especialmente ao se considerar a relação entre a detecção precoce, as perspectivas terapêuticas e a qualidade de vida das mulheres (MELO; SOUZA, 2012).

As modalidades terapêuticas do câncer de mama são indicadas levando sempre em consideração os aspectos biológicos e as características específicas de cada usuária, como idade, presença ou não de comorbidades e preferências; mas, sobretudo, considerando o estadiamento do tumor (INCA, 2010).
Dos artigos pesquisados, analisou-se - perfil sociodemográfico e clínico das mulheres portadoras de câncer de mama, dando ênfase para: média de idade; grau de estudo; estado civil; renda média mensal familiar; atividade ocupacional; e realização de cirurgia de reconstrução mamária para avaliação da qualidade de vida (OV).

A pesquisa apresentou que os fatores supracitados influenciam positiva ou negativamente a OV das mulheres mastectomizadas, envolvendo maturidade das pacientes mais velhas e as expectativas em terem filhos, sendo também relevante o padrão social de mulheres com melhor condição social. Este último aspecto é apontado como elemento que leva as pacientes a serem mais propensas a ter uma recuperação mais rápida e a conseguirem enfrentar melhor os problemas decorrentes do tratamento, em comparação àquelas aquelas com estrato social baixo. Isto é, a condição social alta pode ser um indicativo de mais chances de obter apoio social e psíquico, assim como de melhores condições de moradia. Outro fator está na cirurgia de reconstrução mamária, a qual se tornou um fator positivo para as mulheres mastectomizadas, contribuindo para a elevação da média de QV, principalmente das que possuem parceiros.

Atualmente, os serviços de saúde do Brasil não estão ainda preparados para ofertar uma assistência que garanta bons índices de qualidade de morte, ou seja, o prolongamento da vida com qualidade de vida e dignidade humana. (SILVA et al., 2015). Isso porque podemos observar que a saúde pública do Brasil hoje se apresenta com deficiência na estrutura física, havendo falta de disponibilidade de material-equipamento-medicamentos e carência de recursos humanos. Diante disso, é comum evidenciar a carência na oferta dos cuidados paliativos oncológicos nos serviços, sendo muitas vezes vinculados apenas à clínica da dor nos contextos ambulatoriais. 
Nos artigos estudados, pode-se observar uma preocupação por parte dos autores em relatar a relevância dos cuidados paliativos por parte dos profissionais de saúde, em específico os enfermeiros, visto que estes cuidados são essenciais na atenção para a qualidade de vida destes seres humanos.

\section{Temática dos artigos pesquisados em cuidados paliativos às mulheres com câncer de mama}

Em meio aos métodos terapêuticos do câncer de mama, os cuidados paliativos tornam-se essenciais para o melhor desempenho físico, social e emocional associados à doença, obtendo um papel ativo na melhoria da qualidade de vida das mulheres assistidas. A Organização Mundial de Saúde, no ano de 2002, definiu os cuidados paliativos como uma abordagem ou tratamento para melhorar a qualidade de vida de pacientes e familiares diante de doenças que podem levar à morte.

Trata-se de um cuidado assistencial que reúne habilidades de uma equipe multiprofissional para ajudar o paciente a adaptar-se às mudanças de vida impostas pela doença, e, ao mesmo tempo, para promover ao paciente e a familiares a reflexão necessária para o enfrentamento desta condição de ameaça à vida. Os cuidados paliativos têm a função não somente de aliviar a dor do paciente em tratamento do câncer de mama, mas também de auxiliar na atenção aos sintomas de natureza física, social, emocional e espiritual (SILVA et al., 2015).

De acordo com a Política Nacional de Prevenção e Controle do Câncer, estabelecida na Portaria $n^{\circ} 874 / 2013$, os cuidados paliativos estão inseridos em todos os níveis de atenção à saúde, ou seja, na atenção básica de saúde, na média e na alta complexidade, garantindo, com isso, o direito integral, equânime e universal à saúde do cidadão (MENDES; VASCONCELOS, 2015).
Os cuidados paliativos surgiram no Brasil na década de 1980, no final do período do regime da ditadura militar, em que as assistências de saúde eram predominantemente individuais e fragmentadas. Os pacientes, por sua vez, tinham morte solitária, sem a presença de seus familiares, e muitas vezes morriam sem o conhecimento de sua situação clínica.

Diante disso, o Ministério da Saúde buscou o aperfeiçoamento dos cuidados paliativos nas Unidades de Saúde implementando estratégias incorporadas em políticas de saúde para a atenção oncológica. Segundo Mendes e Vasconcelos (2015), as preocupações com relação aos cuidados paliativos no Brasil se firmaram a partir da Política Nacional de Atenção Oncológica, em 2005, que foi reeditada em 2013, dentro do Plano Estratégico de Controle e Prevenção das DCNT. Contudo, apesar das iniciativas de incorporar esse conceito e essa metodologia, e mesmo havendo fundamentação em bases legais, a rede de assistência à saúde no Brasil ainda não consegue dar conta da implementação e organização dos cuidados paliativos nos três níveis de complexidade do sistema de saúde.

Dessa forma, de acordo com a literatura, para que haja uma assistência efetiva em cuidados paliativos no sistema de saúde, devem ser estabelecidas interlocuções entre as várias áreas de atenção à saúde, com uma organização em que seja preconizada a assistência em cuidados paliativos em todas as suas abrangências, ou seja, na atenção básica, na média e na alta complexidade.

Além destas áreas de atenção, reforça-se ainda a necessidade de que se tenha o desenvolvimento e aperfeiçoamento de programas de cuidados paliativos para os profissionais de saúde que estão na prestação do cuidado junto a estes pacientes.

Neste contexto, o Conselho Internacional das Enfermeiras estabelece que a atuação das enfermeiras no cuidado ao paciente seja fundamental, tanto na atenção e no auxílio do alívio do sofrimento humano, bem como 
para proporcionar qualidade de vida aos clientes e seus familiares, mediante a uma pronta avaliação, identificação e controle da dor e das necessidades físicas, sociais, psicológicas, espirituais e culturais (MENDONÇA; MOREIRA; CARVALHO, 2012).

Contudo, é preciso que esses profissionais sejam capacitados para o tratamento e a assistência nos casos de câncer de mama. De acordo com Silva et al. (2012, p. 462),

A formação na área ontológica deve promover o conhecimento específico e a competência profissional adequada às práticas de trabalho, em toda a sua complexidade e amplitude, sempre com base nas melhores evidências científicas existentes, apoiadas por um sólido julgamento clínico-epidemiológico e princípios éticos, e centradas na melhoria do cuidado (SILVA et al., 2012, p. 462).

Segundo os autores, as enfermeiras manejam um conjunto de ações com conhecimento, habilidade, humanidade e competência, favorecendo, assim, uma relação intersubjetiva no cuidado à mulher com câncer de mama. Para Nascimento et al (2012), o enfermeiro deve ter conhecimento técnico e científico e, essencialmente, a prática para lidar com as consequências da doença, sejam elas de ordem física, social e/ ou emocional. É importante ressaltar ainda que este profissional tem um papel ativo na melhoria da qualidade da assistência prestada, sendo esta realizada de forma eficiente para que minimize o sofrimento da paciente.

Para tanto, os cuidados paliativos são essenciais e devem focar na importância do cuidado integral, no domínio físico, psicológico, social e espiritual. É importante ainda que os cuidados paliativos sejam estendidos para a família, visto que esta é peça relevante para a promoção da qualidade de vida de pacientes com câncer de mama em extrema vulnerabilidade, auxiliando em seu tratamento.
De acordo com Ferreira, Pires e Soares (2012, p.512), "conhecer a interação entre fatores biológicos, comportamentais e ambientais seria então fundamental no planejamento de intervenções eficazes voltadas para o aprimoramento do bem-estar dessa população".

Para isso, o profissional de saúde deve preocupar-se com o lado emocional da paciente, agindo para a melhoria da sua qualidade de vida e de sua família, bem como ajudando a suportar possíveis dores e angústias resultantes de um contexto de morte iminente. Alves et al. (2015) reforçam este pensamento ao afirmar que é importante para os profissionais a compreensão da filosofia da humanização, a qual tem como princípio o cuidado à pessoa doente e o alívio do seu sofrimento, ou seja, o cuidado à pessoa e não apenas à doença.

Desse modo, o profissional que presta assistência ao paciente com câncer desenvolve suas atividades direcionando seus esforços em busca de um objetivo, que é o de prestar uma assistência que atenda as reais necessidades dos pacientes sob seus cuidados.

\section{CONSIDERAÇÕES FINAIS}

O câncer de mama é considerado uma das piores doenças que atinge o ser humano, haja vista seu agravamento à saúde dos pacientes, bem como os tratamentos agressivos e mutilantes envolvidos, e, principalmente o risco iminente de morte. É uma doença que vem nas últimas décadas apresentando uma taxa bruta de incidências.

A extirpação do tumor ou nódulo por meio da mastectomia torna-se uma fase traumatizante no tratamento da doença para as mulheres, em que ficam evidenciados sentimentos de tristeza, ansiedade, vergonha, exclusão e mutilação devido aos efeitos colaterais das drogas quimioterápicas, da radioterapia e da cirurgia. Há ainda sentimentos negativos provocados pela 
ruptura de seu ambiente habitual; alteração de costumes e hábitos; e capacidade de autorrealização e de cuidado pessoal.

Diante deste contexto, é importante que os profissionais de enfermagem despertem para a importância de cuidados paliativos que visem proporcionar um tratamento mais humanizado e enriquecedor. Assim, o enfermeiro deve ajudar a paciente com orientações e esclarecimentos sobre a doença, bem como contribuir com diversos fatores que possam favorecer uma melhor qualidade de vida a estas mulheres, com cuidados paliativos que possibilitem a superação dos obstáculos provocados pela doença.

Detectou-se neste estudo que os cuidados paliativos às mulheres portadoras de câncer de mama em estado de vulnerabilidade extrema estão fundamentados num sistema de valores humanísticos universais, tais como a amabilidade, o respeito e o afeto por si e pelos outros. O cuidado paliativo de enfermagem está na promoção do diálogo, no saber ouvir, na segurança, na valorização das queixas e no apoio aos familiares. Estas ações incluem medidas terapêuticas para o controle dos sintomas físicos; intervenções psicoterapêuticas; e apoio espiritual ao paciente do diagnóstico ao óbito. Para os familiares, as ações se dividem entre apoio social e espiritual e intervenções psicoterapêuticas do diagnóstico ao período do luto.

Contudo, é importante que os enfermeiros reflitam constantemente sobre a importância da prática dos cuidados baseada na integralidade e na inserção do acolhimento e da humanização. Reforça-se, para a sensibilização do profissional no procedimento dos cuidados paliativos, o levar em consideração aspectos cultural, religiosa e social das mulheres.

O estudo mostrou que os cuidados paliativos às pacientes com câncer de mama ganharam seu espaço e se transformaram em um método de cuidar que veio para proporcionar uma nova metodologia da assistência com resultados positivos, tanto para a paciente como para a sua família. Esta pesquisa tem relevância para o conhecimento sobre o câncer de mama e aponta para a necessidade de haver mais estudos que vislumbrem a temática com abordagens diversas. 


\section{REFERÊNCIAS}

ALVES, Railda Fernandes et al. Cuidados paliativos: desafios para cuidadores e profissionais de saúde. Fractal: Revista de Psicologia, v. 27, n. 2, p. 165-176, 2015.

\section{BREASTCANCER.ORG. Guia para entender o laudo médico de} câncer de mama. 2010. Disponível em: www.cancer1source.org. Acesso em: 3 jan. 2017.

BRASIL. Ministério da Saúde. Portaria no 876, de 16 de maio de 2011. Dispõe sobre a aplicação da Lei no 12.732, de 22 de novembro de 2012, que versa a respeito do primeiro tratamento do paciente com neoplasia maligna comprovada no âmbito do Sistema Único de Saúde (SUS). Diário Oficial da União, 17 mar. 2013.

FERLAY, J. et al. Cancer incidence and mortality worldwide: sources, methods and major patterns in GLOBOCAN 2012. International journal of cancer, 136(5), E359-E386.

FERREIRA, Renatha El Rafihi; PIRES, Maria Laura Nogueira; SOARES, Maria Rita Zoéga. Sono, Qualidade de Vida e Depressão em Mulheres no Pós-tratamento de Câncer de Mama. Psicologia: Reflexão e Crítica, v. 25, n. 3, p. 506-513, 2012. Disponível em: http://www.scielo.br/scielo.php?script=sci_ arttext\&pid=S0102-7972201200030001. Acesso em: 22 jan. 2017.

HOCHMAN, Bernardo et al. Desenhos de pesquisa. Acta Cirúrgica Brasileira, v. 20, 2005. Supl. 2.

INSTITUTO NACIONAL DE CÂNCER. Liga Norte-Riograndense Contra o Câncer. Estimativa 2018: incidência de câncer no Rio Grande do Norte. 2018. Disponível em: http://www1.inca.gov.br/ estimativa/2018/rio-grande-norte-natal.asp. Acesso em: 20 fev. 2019.

INSTITUTO NACIONAL DO CÂNCER. ABC do câncer: abordagens básicas para o controle do câncer. Rio de Janeiro: Inca, 2011. p. 128. Disponível em: http://globocan.iarc.fr. Acesso em: 4 jan. 2017.

INSTITUTO NACIONAL DO CÂNCER. Mama. 2010. Disponível em: http://www2.inca.gov.br/wps/wcm/connect/tiposdecancer/site/ home/mama. Acesso em: 30 jan. 2017.

INSTITUTO NACIONAL DE CÂNCER JOSÉ ALENCAR GOMES DA SILVA. Atlas de mortalidade por câncer. Rio de Janeiro: Instituto Nacional de Câncer José Alencar Gomes da Silva, 2011. Disponível em: http://dx.doi.org/10.1590/0102-311X00048514. Acesso em: 3 jan. 2017. 


\section{LIGA CONTRA O CANCER. Liga Norte Riograndense na luta}

contra o Câncer de Mama. Natal: Liga Norte Riograndense Contra o Câncer, 2018. Disponível em: http://www.ligacontraocancer.com. br/a-liga/novidades/201/outubro-rosa-2018. Acesso em: 20 fev. 2019.

MELO, Maria Carmen Simões Cardoso de; SOUZA, Ivis Emília de Oliveira. Ambiguidade: modo de ser da mulher na prevenção secundária do câncer de mama. Esc Anna Nery (impr.), v. 16, n. 1, p. 41-48, 2012. Disponível em: http://www.scielo.br/pdf/ean/v16n1/ v16n1a06.pdf. Acesso em: 30 jan. 2017.

MENDES, K. D. S.; SILVEIRA, R. C. C. P.; GALVÃO, C. M. Revisão integrativa: método de pesquisa para a incorporação de evidências na saúde e na enfermagem. Texto contexto - enferm., Florianópolis, v. 17, n. 4, 2008. Disponível em: http://dx.doi. org/10.1590/S0104-07072008000400018. Acesso em: 3 jan. 2017.

MENDES, Ernani Costa; VASCONCELLOS, Luiz Carlos Fadel de. Cuidados paliativos no câncer e os princípios doutrinários do SUS. Saúde Debate, Rio de Janeiro, v. 39, n. 106, p. 881-892, 2015.

MENDONCA, Ana Carolina Abeid; MOREIRA, Marléa Chagas; CARVALHO, Vilma de. Atenção paliativa oncológica em Unidade de Terapia Intensiva: um estudo da produção científica da enfermagem. Esc. Anna Nery, Rio de Janeiro, v. 16, n. 4, p. 817-823, dez. 2012.

ROBSON, Mark et al. American Society of Clinical Oncology policy statement update: genetic and genomic testing for cancer susceptibility. J Clin Oncol., v. 28, n. 5, p. 893-901. 2010. Disponível em: http://dx.doi.org/10.1590/S0104-07072013000200031.

Acesso em: 3 jan. 2017.

SILVA, Marcelle Miranda da et al. Cuidados paliativos na assistência de alta complexidade em oncologia: percepção de enfermeiros.

Esc Anna Nery, v. 19, n. 3, p. 460-466, 2015.

SILVA, Josiane Travençolo da et al Prática profissional de enfermeiras que cuidam de pacientes com câncer em hospitais gerais. Rev Bras Enferm, Brasília, v. 65, n. 3, p. 460-465, maio/jun. 2012. Disponível em: http://www.scielo.br/pdf/reben/v65n3/v65n3a10.pdf. Acesso em: 30 jan. 2017.

WHITEMORE, Robin; KNAFL, Kathleen. The integrative review: update methodology. J Adv Nurs, v. 52, n. 5, p. 546-553, 2005. Disponível em: http://users.phhp.ufl.edu/rbauer/EBPP/whittemore_ knafl_05.pdf. Acesso em: 27 jan. 2017. 